\title{
CHRONOLOGY DEVELOPMENT AND CLIMATE RESPONSE ANALYSIS OF SCHRENK SPRUCE (PICEA SCHRENKIANA) TREE-RING PARAMETERS IN THE URUMQI RIVER BASIN, CHINA
}

\author{
FENG CHEN, YUJIANG YUAN, WENSHOU WEI, SHULONG YU, YANG LI, RUIBO ZHANG, \\ TONGWEN ZHANG and HUAMING SHANG \\ Institute of Desert Meteorology, China Meteorological Administration, Key Laboratory of Tree-ring Physical and Chemic \\ Research of China Meteorological Administration, Key Laboratory of Tree-ring Ecology of Uigur Autonomous Region, \\ No 46 Jianguo Road, 830002 Urumqi, China
}

\begin{abstract}
Seven different tree-ring parameters (total tree-ring width, earlywood width, latewood width, maximum latewood density, minimum earlywood density, average earlywood density, and average latewood density) were obtained from Schrenk spruce in the Urumqi River Basin, China. The chronologies were analyzed individually and then compared with each other. The relationships between the different tree-ring parameters and climate data (Daxigou) are also presented. Earlywoodrelated parameters (earlywood width, minimum density, and earlywood density) were more sensitive to climate than those of latewood. Temperature (July) was found to be the most strongly related to the earlywood density. Based on the results of climate response analysis, the potential of tree-ring chronologies from this species to provide climate reconstructions in the Urumqi River Basin has been established. This study demonstrates that the use of tree-ring density data can increase the climate information obtained from tree-ring and should lead to improved paleoclimate reconstructions in Central Asian.
\end{abstract}

Keywords: Picea schrenkiana; dendroclimatology; tree-ring width; tree-ring density.

\section{INTRODUCTION}

Dendroclimatic studies have been done at sites across the northern region of Xinjiang (Yuan and Li, 1999; Yuan et al., 2001; Yuan et al., 2003; Wei et al., 2008; Chen et al., 2008; Chen et al., 2009). The studies demonstrated the high dendroclimatic potential of the local conifers for developing reliable reconstructions of the climate (precipitation and temperature) during the past three centuries over various parts of the Tianshan Mountains. Some studies indicated the high dendroclimatic potential of tree-ring density in the Tianshan Mountains (Zhang and Li, 1998; Yuan et al., 2008; Chen et al., 2009). For the first time, they used tree-ring density along with tree-ring width to model the tree growth-climate response. Their study showed high correlation of maximum density with temperature. They presented the reconstructions of summer temperatures back to the mid $18^{\text {th }}$

Corresponding author: Y J. Yuan

e-mail: cycfqq@sohu.com

ISSN 1897-1695 (online), 1733-8387 (print) C 2010 GADAM Centre, Institute of Physics, Silesian University of Technology.

All rights reserved. century. Their results of calibration and verification tests indicated that the quality of these reconstructions was equivalent to many of those from Europe and North America. To better understand the tree growth-climate relationships in the Urumqi River Basin, densitometric analysis of Schrenk spruce (Picea schrenkiana Fisch. et Mey.) from Yuejing bridge site (YJQ) was investigated. This is the first tree-ring density research in this region. Various parameters of tree-ring density were assessed for their usefulness in providing stable reconstructions of climate.

\section{MATERIALS AND METHODS}

Twenty-one trees at the Yuejing bridge site (Fig. 1) were sampled with increment borers $(5 \mathrm{~mm}$ and $12 \mathrm{~mm})$. Two cores $(5 \mathrm{~mm})$ and one core $(12 \mathrm{~mm})$ were taken from each tree in the field. In total 50 cores $(5 \mathrm{~mm})$ and 21 cores $(12 \mathrm{~mm})$ were collected at the Yuejing bridge site. To minimize non-climatic influences on tree growth, only trees with no obvious injury or disease were sampled (Table 1). 
Table 1. Site information for standardized tree-ring chronologies.

\begin{tabular}{lcccccc}
\hline Site & Longitude(N) & Latitude(E) & Series & Elevation $(\mathbf{m})$ & Slope direction & Slope \\
\hline Yuejing bridge $(\mathrm{YJQ})$ & $43^{\circ} 07^{\prime}$ & $87^{\circ} 05^{\prime}$ & 21 & $2550-2660$ & $\mathrm{NE}$ & $15-25^{\circ}$ \\
\hline
\end{tabular}

The cores $(5 \mathrm{~mm})$ were mounted and prepared following standard procedures (Stokes and Smiley, 1968). Annual ring widths were measured to a precision of 0.01 $\mathrm{mm}$ with a Velmex measuring system at Institute of Desert and Meteorology, China Meteorological Administration, China. The cores $(12 \mathrm{~mm})$ were processed for density measurements with a Dendro-2003 tree-ring workstation at Key Laboratory of Tree-ring Physical and Chemical Research of China Meteorological Administration. To obtain good measurements, the following steps (Schweingruber et al., 1978) were adopted.

Seven types of tree-ring parameters (total tree-ring width, earlywood width, latewood width, maximum density, minimum density, earlywood density, and latewood density) were obtained. The boundary between earlywood and latewood was set for each ring at the midpoint between maximum and minimum density. The data obtained from Dendro-2003 tree-ring workstation were converted into TUCSON format using Program SELTOTUC. Program COFECHA (Holmes, 1983) was used for controlling cross-matching quality of the ring width series ( $5 \mathrm{~mm}$ and $12 \mathrm{~mm}$ ). We used the program ARSTAN to detrend the ring width and density sequences using negative exponential curve and to average the standardized ring width and density sequences into the master chronologies (Cook and Kairiukstis, 1990). The variance in chronologies was stabilized in the chronology compilation process with the Briffa RBAR-weighted method, which uses average correlations between series in combination with sample size each year to make adjustments in the variance for changes in sample size (Osborn et al., 1997). The expressed population signal (EPS) (Wigley et

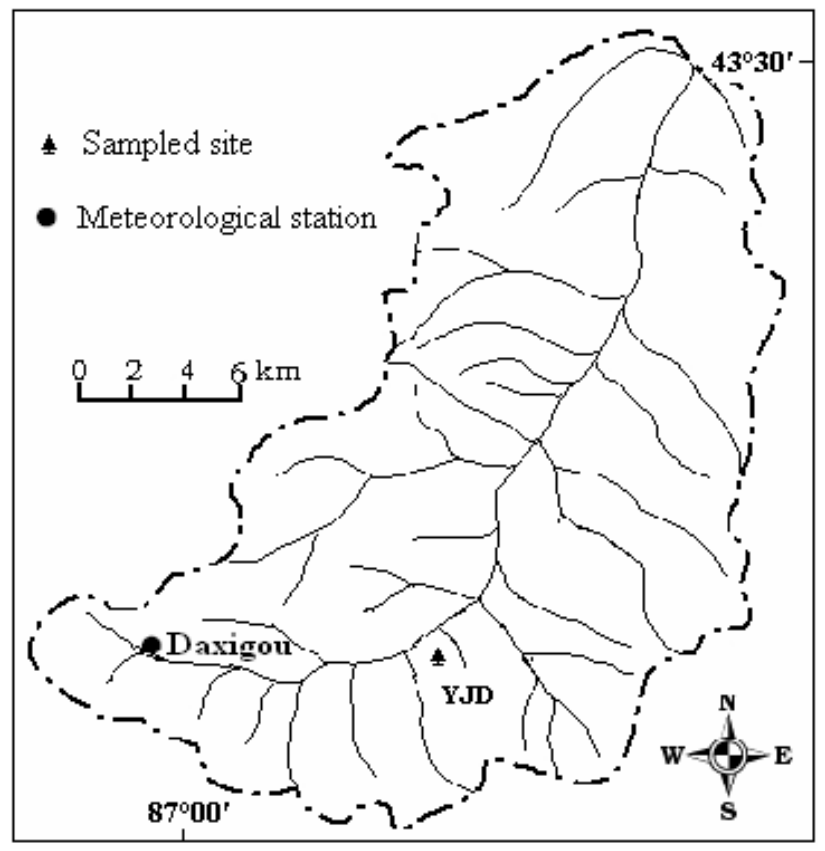

Fig. 1. Location map of sampling site and meteorological station. al., 1984) with a threshold value of 0.85 was used to evaluate the most reliable time span of the chronology.

The relationships between the tree-ring data and the climatic data were analyzed using SPSS software package. In the correlation analysis, local climate data (Daxigou, $43^{\circ} 07^{\prime} \mathrm{N}, 87^{\circ} 05^{\prime} \mathrm{E}$, altitude $3000 \mathrm{~m}$ a.s.1; Fig. 2) along with each ring parameter, were examined from previous March to current August.

Leave-one-out method (Blasing et al., 1981) was employed to test the reliability of the climate reconstruction models, included the reduction of error (RE), the product means test (PMT), and the Sign Test (ST) (Fritts, 1976; Cook and Kairiukstis, 1990).

\section{RESULTS AND DISCUSSION}

\section{Chronology development}

The total tree-ring width data was checked by the program COFECHA first. The density series obtained from the Dendro-2003 were checked for missing rings and dating errors based on the total ring width crossmatching results. Errors were corrected by using Dendro2003 tree-ring workstation. Table 2 shows the statistics of the chronologies produced by the standardization program ARSTAN (using negative exponential curve) for each of the seven different chronologies based on the different tree-ring parameters. All series of tree-ring width and density are presented in Fig. 3, respectively. In general, higher mean sensitivity (MS), standard deviation (SD), mean correlation between trees (R), signal to noise ratio (SNR) of tree-ring width parameters are believed to indicate a greater climatic influence on tree growth. However, mean sensitivity (MS), standard deviation (SD), mean correlation between trees (R), signal to noise ratio (SNR) of ring density parameters are low. The den-

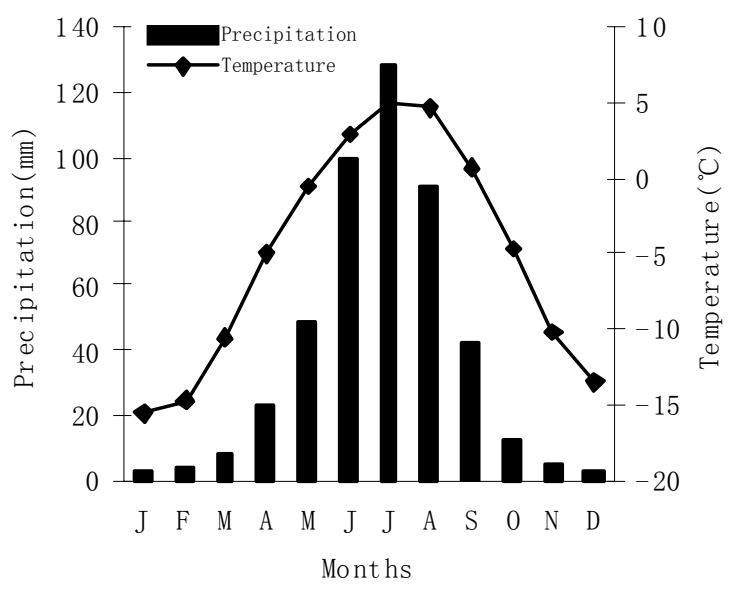

Fig. 2. Mean temperature and precipitation at Daxigou, based on longterm averages. 
Table 2. Common period statistics of Schrenk Spruce tree-ring parameters.

\begin{tabular}{|c|c|c|c|c|c|c|}
\hline Chronology & MS & SD & $\mathbf{R}$ & SNR & EPS & PCA1 \\
\hline Total ring width & 0.231 & 0.240 & 0.393 & 11.017 & 0.917 & 44 \\
\hline Latewood width & 0.176 & 0.195 & 0.236 & 5.261 & 0.840 & 31 \\
\hline Latewood density & 0.056 & 0.052 & 0.182 & 6.311 & 0.863 & 25 \\
\hline Maximum density & 0.060 & 0.056 & 0.187 & 3.912 & 0.796 & 17 \\
\hline Earlywood width & 0.247 & 0.256 & 0.371 & 10.006 & 0.909 & 26 \\
\hline Minimum density & 0.065 & 0.078 & 0.336 & 8.616 & 0.896 & 26 \\
\hline Earlywood density & 0.047 & 0.063 & 0.336 & 8.584 & 0.896 & 27 \\
\hline
\end{tabular}

sity variations appear as mirror images of the tree-ring width variations. Mean correlation between the trees represents the strength of the common signal among the series. Ring width, earlywood width, earlywood density, and minimum density series indicate moderately higher values of mean correlation between trees than the late- wood width, latewood and maximum density series. Percent variance accounted for by the first eigenvector of ring width series is higher than ring density series. On the whole, from Table 2, the parameters of total ring width, earlywood density, and minimum density can be interpreted as having strong regional climate signal and, there-
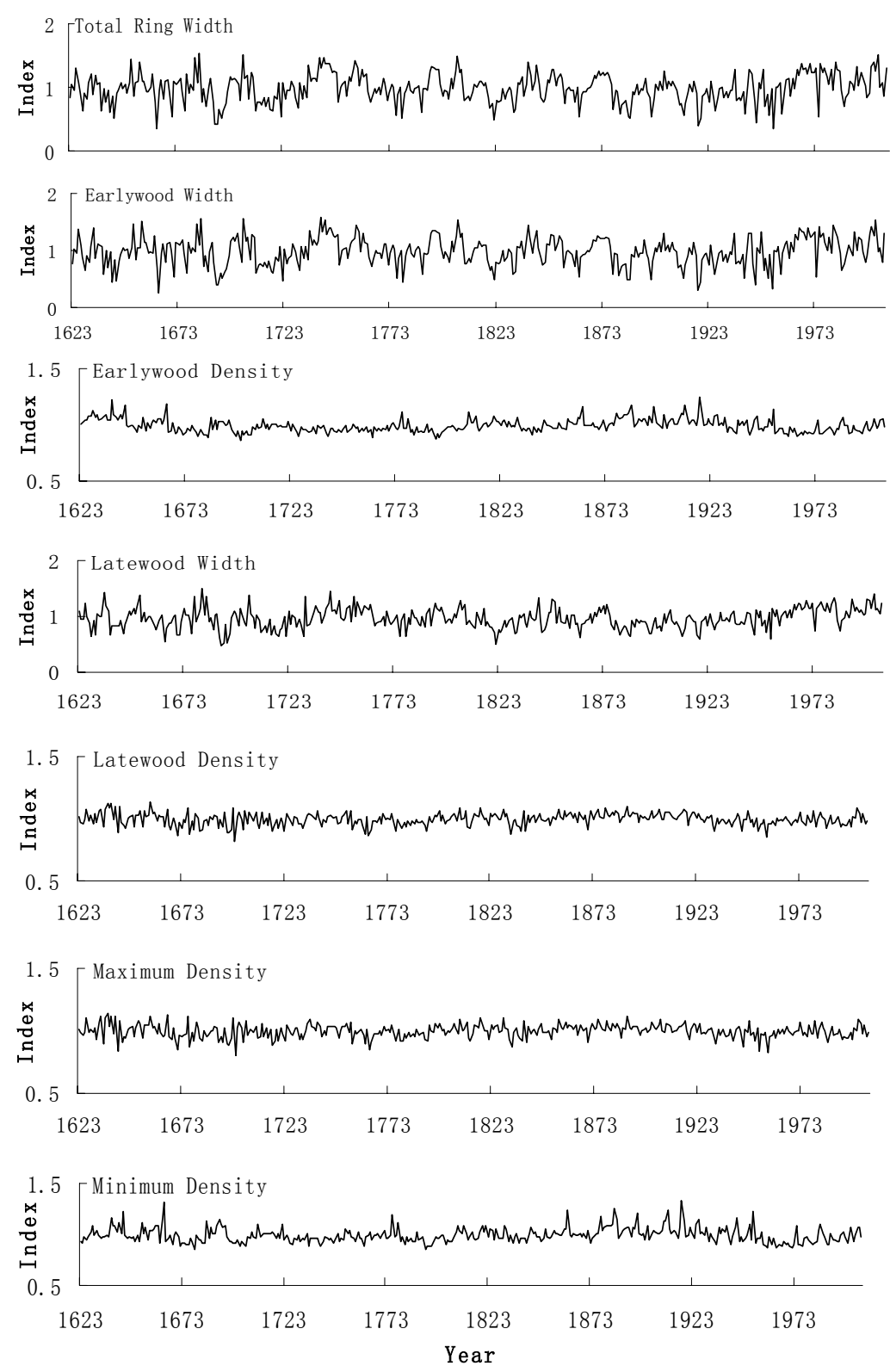

Fig. 3. Tree-ring index chronologies of Schrenk Spruce from YJD site. 
Table 3. Cross correlations between the different chronologies for the common time interval 1623-2006.

\begin{tabular}{|c|c|c|c|c|c|c|}
\hline Chronology & $\begin{array}{c}\text { Tree-ring } \\
\text { width }\end{array}$ & $\begin{array}{l}\text { Latewood } \\
\text { width }\end{array}$ & $\begin{array}{c}\text { Latewood } \\
\text { density }\end{array}$ & $\begin{array}{c}\text { Maximum } \\
\text { density }\end{array}$ & $\begin{array}{c}\text { Earlywood } \\
\text { width }\end{array}$ & $\begin{array}{c}\text { Minimum } \\
\text { density }\end{array}$ \\
\hline Latewood width & $0.840^{* *}$ & & & & & \\
\hline Latewood density & $0.131^{*}$ & 0.037 & & & & \\
\hline Maximum density & $0.307^{* *}$ & $0.193^{* *}$ & $0.955^{*}$ & & & \\
\hline Earlywood width & $0.988^{* *}$ & $0.793^{* *}$ & $0.157^{* *}$ & $0.331^{* *}$ & & \\
\hline Minimum density & $-0.734^{* *}$ & $-0.642^{* *}$ & $0.190^{* *}$ & -0.023 & $-0.727^{* *}$ & \\
\hline Earlywood density & $-0.618^{* *}$ & $-0.530^{* *}$ & $0.400^{* *}$ & $0.204^{* *}$ & $-0.611^{* *}$ & $0.893^{\star *}$ \\
\hline
\end{tabular}

*Significant at or over the $95 \%$ confidence level.

${ }^{*}$ Significant at or over the $99 \%$ confidence level.

fore, considered for further modeling of tree growth with climate.

\section{Correlations between the different parameters}

The correlations in Table 3 show highly significant differences between the chronologies. Most of the correlation coefficients are significant at the $99 \%$ confidence level. Virtually all of the coefficients between earlywood density chronologies (i.e. minimum density, earlywood density) and ring width chronologies (i.e. total ring width, earlywood width) were negatively significant. This implies that wood density will be lower when the tree grew faster in this species. Because very high positive correlation coefficients are observed between similar types of measurements, such as between total tree-ring width and earlywood width (0.988), total ring width and latewood width (0.84), maximum density and average latewood density (0.955), minimum density and average earlywood density (0.893), etc., it would not be statistically appropriate to use the members of each pair together. Tree-ring width chronologies were negatively correlated with density chronologies, such as between earlywood width and earlywood density (-0.611). Latewood density chronology was positively correlated with earlywood density chronology (0.400). This correlation analysis suggests there is no advantage in using the high relation tree-ring parameters in the same model, but the seven tree-ring parameters could provide much climatic information for paleoclimatical study than is provided by total tree-ring width alone.

\section{Climate response analysis}

In the view of the coefficients of all the RFs (Table 4), 17 significant coefficients occurred in growth season (April-August). Nearly all of the coefficients between ring width parameters and precipitation of late previous growth season (August) and the current growing season (June) are positively significant, but coefficients between tree-ring width parameters and temperature are negatively significant in the same period. 22 significant coefficients in temperature are more than 10 significant coefficients in precipitation. Correlations between earlywood density and temperatures of current year June and July reveal significant responses $(p<0.01)$. Significant $(p<0.01)$ positive correlations with August temperature are also obtained using the latewood density parameters. This indicates that Schrenk spruce is better at reflecting temperature than precipitation conditions in the Urumqi River Basin.

To investigate the climate in more detail, we screened the tree-ring chronologies in correlation analysis with the seasonal combinations of temperatures and precipitation from previous March to current August. Earlywood and minimum densities show significant positive response to temperature of vegetation period (from April to July). The best correlation is 0.651 between earlywood density and temperature (July). The best seasonal combination correlation is 0.617 between earlywood density and temperature (June-July). This is mainly because water deficit in early stage of growing season suppresses rapid expan-

Table 4. Summary of the significant response function coefficients $(p<0.05)$.

\begin{tabular}{|c|c|c|c|c|c|c|c|c|c|c|c|c|c|c|c|c|c|c|}
\hline Month & $\mathbf{M}$ & $\mathbf{A}$ & $\mathbf{M}$ & $\mathbf{J}$ & $\mathbf{J}$ & $\mathbf{A}$ & $\mathbf{S}$ & $\mathbf{O}$ & $\mathbf{N}$ & D & $\mathbf{J}$ & $\mathbf{F}$ & $\mathbf{M}$ & $\mathbf{A}$ & $\mathbf{M}$ & $\mathbf{J}$ & $\mathbf{J}$ & $\mathbf{A}$ \\
\hline \multicolumn{19}{|c|}{ RFs with local rainfall } \\
\hline Total ring width & & & & & & + & & & & & & & & & & + & & \\
\hline Earlywood width & & & & & & + & & & & & & & & & & + & & \\
\hline Earlywood density & & & & & & & & & & & & & & - & & & & \\
\hline Latewood width & & & & & & + & & & & & & & & & & & & \\
\hline Latewood density & & & & & & + & & & & & & & & & & & & \\
\hline Maximum density & + & & & & & + & & & & & & & & & & & & \\
\hline Minimum density & & & & & & & & & & & & & & - & & & & \\
\hline \multicolumn{19}{|c|}{ RFs with local temperature } \\
\hline Total ring width & & & & & - & - & & & & & & & & & & - & & \\
\hline Earlywood width & + & & & & - & - & & & & & & & & & & - & & \\
\hline Earlywood density & & & & & & + & & & & & & & & + & & + & + & \\
\hline Latewood width & & & & + & & & & & & & & & & & & & - & \\
\hline Latewood density & & & & & & & & & & & & & & & & & & + \\
\hline Maximum density & & & & & & & & & & & & & & & & & & + \\
\hline Minimum density & & & & & + & + & & & & & & & & + & & + & + & \\
\hline
\end{tabular}


sion of tracheids (Fritts, 1976). Tracheid diameter contributes to the density variations. Water deficit in the growing season suppresses enlargement of tracheids. When tracheids become narrower, the proportion of cell wall in the annual ring increases because of the reduction of lumen size (Pant et al., 2000). June and July are the hottest months of the year. Evaporation increases with the rise in temperatures of June-July, which accelerates the already existing water stress. Therefore, the temperature in summer is the main limiting factor for tree radial growth. This explains the high value of earlywood density in narrow rings and the corresponding opposite pattern of relationship of density and ring width with climate in response function analyses.

\section{Assessment of potential for climate reconstruction}

Based on the above response function analysis results, earlywood density chronology was selected to reconstruct temperature (July). The stepwise regression model obtained was:

$\mathrm{T}=9.258+0.003 \mathrm{YJD}$

The RE (0.376), the sign test $\left(12^{-} / 36^{+}\right)$and product means test statistics (5.554) were both found to be significant at the 0.001 level (Table 5). The reconstruction accounts for $42.4 \%$ of the actual temperature variance during 1959-2006, which is not very high but significant. These results indicated that the model used here passed the critical tests for verification and was optimized by achieving the greatest predictive capability for the fewest independent variables. Estimated series of temperature are presented in Fig. 4 along with the observed data for common period from 1959 to 2006.

The newly developed temperature reconstruction in the Urumqi River Basin is compared with long temperature records in Yili $\left(44^{\circ} 34^{\prime} \mathrm{N}, 80^{\circ} 51^{\prime} \mathrm{E}\right)$ to assess patterns of past temperature variability. The temperature records (July to August) in Yili is based on latewood density parameters, using the negative exponential curve for series detrending. Correlation between the reconstruction of Yili and the reconstruction of Urumqi River Basin describes a generally lower agreement $(0.298, P<0.001)$,

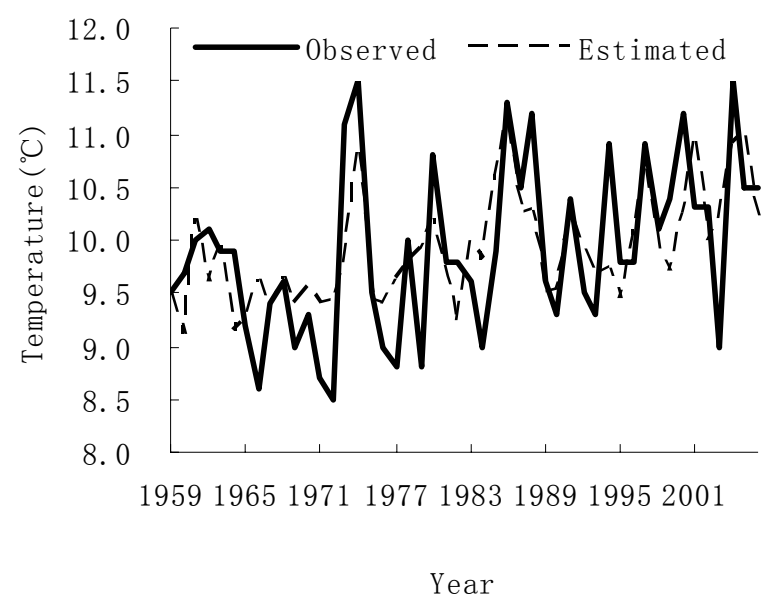

Fig. 4. Comparison of actual and reconstructed temperature from 1959 to 2006 .

but increases coherence after 20-year low-pass filtering. The correlation coefficient after 20-year low-pass filtering is $0.436(P<0.001$; Fig. 5).

This study examines the potential utility of density parameters of conifers for dendroclimatic studies in the Urumqi River Basin. Dendroclimatic reconstruction of temperature (July) in the Urumqi River Basin using treering density of Schrenk Spruce is a new research to attempt to use the density parameters for a Xinjiang species. Many investigators (Polge, 1970; Parker and Henoch, 1971; Schweingruber et al., 1978; Briffa et al., 1988; Briffa et al., 1992; Luckman et al., 1997 ; Davi et al., 2001; Wilson and Luckman, 2003; Büntgen et al., 2005; Büntgen et al., 2006; Büntgen et al., 2008; Wang et al., 2009) found that latewood width and maximum density were significantly associated with climate in their study on various European and North American species. Our studies also revealed that the latewood density parameters from Schrenk spruce were effective in establishing the tree growth climate relationship in Yili and Urumqi River Basin. However, it is observed that earlywood density parameters are the major contributor in

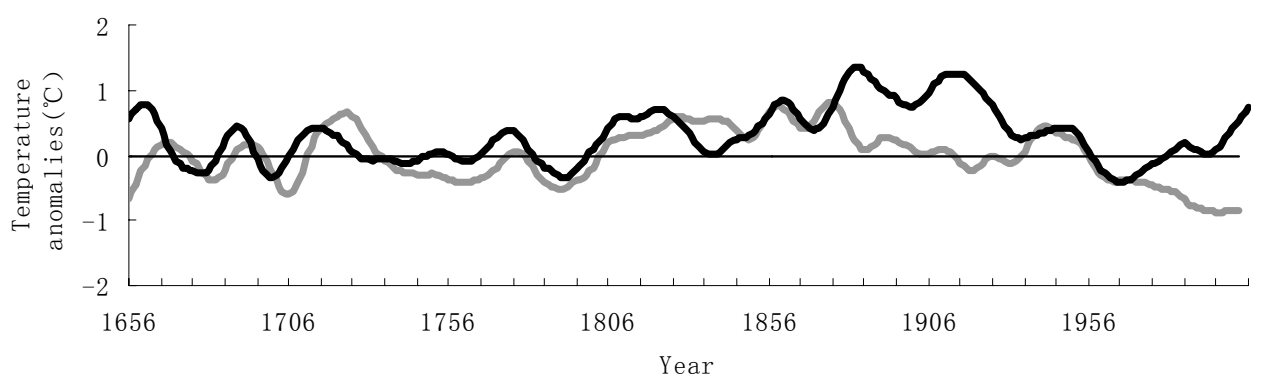

Fig. 5. The comparison between the 20-year low-pass filtered temperature reconstruction series.

Table 5. Leave-one-out, cross-validation statistics for July temperature reconstruction in the Urumqi River Basin.

\begin{tabular}{lccccc}
\hline Site & $\mathbf{r}$ & $\mathbf{r}^{2}$ & $\mathbf{R E}$ & $\mathrm{ST}$ & PMT \\
\hline Urumqi River Basin & 0.651 & 0.424 & 0.376 & $12-136^{+}$ & 5.554
\end{tabular}


dendroclimatic estimation in this study. The results of our analysis are similar to some studies (Xiong et al., 1998; Pant et al., 2000) demonstrated that earlywood tree-ring parameters (earlywood density, minimum density, and earlywood width) were also sensitive to climate. Climate may strongly influence all types of tree-ring data (total ring width, early and latewood width, early and latewood density) depending on species and site conditions. The results indicate that understanding of physiological characteristics of a species is important when reconstructing the past climate. This study clearly establishes the potential for using density parameters of Tianshan Mountains conifers in dendroclimatic studies and brings out the role of earlywood density for temperature reconstruction. This increases the options available for reconstructions of climate using tree-ring data over a large area of Tianshan Mountains using longer chronologies.

\section{ACKNOWLEDGEMENTS}

This work was supported by supported by Meteorology Public Welfare Industry Research Special Project (GYHY200806011), NSFC Project (No. 40975056), the basic research project of Science and Technology Ministry of China (2007FY220200), the Young Scientists Project of Xinjiang Meteorology Bureau (201033), the Foundation of Xinjiang Laboratory of Tree-ring Ecology (XJYS0911-2009-01). I thank all members, especially Dr Ulf Büntgen and Daniel Nievergelt, for all their help. We also thank the reviewers whose comments greatly benefitted this manuscript.

\section{REFERENCES}

Blasing TJ, Duvick DN and West DC, 1981. Dendroclimatic calibration and verification using regionally averaged and single station precipitation data. Tree-ring Bulletin 41: 37-43.

Briffa KR, Jones PD and Schweingruber FH, 1988. Summer temperature patterns over Europe: a reconstruction from $1750 \mathrm{AD}$ based on maximum latewood density indices of conifers. Quaternary Research 30(1): 36-52, DOI 10.1016/0033-5894(88)90086-5.

Briffa KR, Jones PD and Schweingruber FH, 1992. Tree-ring reconstructions of summer temperature patterns across western North America since 1600. Journal of Climate 5(7): 735-754.

Büntgen U, Esper J, Frank DC, Nicolussi K and Schmidhalter M, 2005. A 1052-year tree-ring proxy of Alpine summer temperatures. Climate Dynamics 25(2-3): 141-153, DOI 10.1007/s00382-005-00281.

Büntgen U, Frank D C, Nievergelt D and Esper J, 2006. Summer temperature variations in the European Alps, AD 755-2004. Journal of Climate 19: 5606-5623.

Büntgen U, Frank D C, Grudd H and Esper J, 2008. Long-term summer temperature variations in the Pyrenees. Climate Dynamics 31(6): 615-631, DOI 10.1007/s00382-008-0390-x.

Chen F, Yuan YJ, Yu SL and Ding L, 2008. Reconstruction and Analysis of Precipitation of the Basin of Hutubi River in middle Tianshan Mountians during the last 313Years. Arid Zone Research 26(1): 130-134 (in Chinese).

Chen J, Wang LL, Zhu HF and Wu P, 2009. Reconstructing mean maximum temperature of growing season from the maximum density of the Schrenk Spruce in Yili, Xinjiang, China. Chinese Science Bulletin 54(1): 1-9.

Holmes RL, 1983. Computer assisted quality control in tree-ring dating and measurement. Tree-Ring Bulletin 43: 69-75.

Cook ER and Kairiukstis A, 1990. Methods of dendrochronologyApplications in environmental sciences. Kluwer Academic Publishers: $394 \mathrm{pp}$.

Davi N, D'Arrigo RD, Jacoby G.C, Buckley BM and Kobayashi O, 2001. Warm-season annual to decadal temperature variability for Hokkaido, Japan, inferred from maximum latewood density (AD 1557-1990) and ring width data (AD 1532-1990). Climatic Change 52(1-2): 201-217, DOI 10.1023/A:1013085624162.

Fritts HC, 1976. Tree-Rings and Climate. New York, Academic Press: $567 \mathrm{pp}$.

Luckman BH, Briffa KR, Jones PD and Schweingruber FH, 1997. Treering based reconstruction of summer temperatures at the Columbia Icefield, Alberta, Canada, $\mathrm{AD}$ 1073-1983. The Holocene 7(4): 375-89, DOI 10.1177/095968369700700401.

Osborn TJ, Briffa KR. and Jones PD, 1997. Adjusting variance for sample-size in tree-ring chronologies and other regional mean timeseries. Dendrochronologia 15: 89-99.

Pant GB, Kumar KR, Borgaonkar HP Okada N, Fujiwara T and Yamashita K, 2000. Climatic response of Cedrus deodara tree-ring parameters from two sites in the western Himalaya. Canadian Journal of Forest Research 30(7): 1127-1135, DOI 10.1139/cjfr-30-71127.

Parker ML and Henoch WES, 1971. Increment core planer for X-ray densitometric sample preparation. Wood Science 11(1): 33-36.

Polge H, 1970. The use of X-ray densitometric methods in dendrochronology. Tree-Ring Bulletin 30: 1-10.

Schweingruber FH, Fritts HC, Bräker OU, Drew LG and Schär E, 1978.The X-ray technique as applied to dendroclimatology.TreeRing Bulletin 38: 61-91.

Stokes MA and Smiley TL, 1968. An introduction to tree-ring dating. Chicago, University of Chicago Press: 111pp.

Wang LL, Duan JP, Chen J, Huang L and Shao XM, 2009. Temperature reconstruction from tree-ring maximum density of Balfour spruce in eastern Tibet, China. International Journal of Climatology 30: 972-979, DOI: 10.1002/joc.2000.

Wei WS, Yuan YJ, Yu SL and Zhang RB, 2008. Climate change in recent 235 year and trend prediction in Tianshan Mountainous. Journal of Desert Research 28(5): 803-809 (in Chinese).

Wigley TML, Briffa K and Jones PD, 1984. On the average value of correlated time series, with applications in dendroclimatology and hydrometeorology. Journal of Climate and Applied Meteorology 23: 201-213.

Wilson RJS and Luckman BH, 2003. Dendroclimatic reconstruction of maximum summer temperatures from upper treeline sites in Interior British Columbia, Canada. The Holocene 13: 851-861, DOI 10.1191/0959683603hl663rp.

Xiong LM, Naoki O, Takeshi F, Saddaki O and Palmer JG, 1998. Chronology development and climate response analysis of different New Zealand pink pine(Halocarpus biformis) tree-ring parameters. Canadian Journal of Forest Research 28(4): 566-573, DOI 10.1139/cjfr-28-4-566.

Yuan YJ and Li JF, 1999. Reconstruction and analysis of 450 years winter temperature series in the Urumqi River source of Tianshan Mountains. Journal of Glaciology and Geocryology 21: 64-70 (in Chinese).

Yuan YJ, Li JF and Zhang JB, 2001. 348-year precipitation reconstruction from tree-rings for the north slope of the middle Tianshan mountains. Acta Meteorologica Sinica 15(1): 95-104.

Yuan YJ, Jin LY, Shao XM, He Q, Li ZZ and Li JF, 2003. Variations of the spring precipitation day numbers reconstructed from tree rings in the Urumqi River drainage,Tianshan Mts. Over the last 370 years. Chinese Science Bulletin 48(14): 1507-1510.

Yuan YJ, Esper J, Wei WS, Nievergelt D, Verstege A, Yu SL and Zhang RB, 2008. Development, correlation and climate signal analysis of three Spruce chronologies of tree-ring maximum density from upper tree line in the western Tianshan Mountains of Xinjiang. Arid Land Geography 31: 560-566 (in Chinese).

Zhang ZH and Li J, 1998. Precipitation and average monthly high temperature in Jimsar County, Xinjiang. Acta Meteorologica Sinica 56: 77-86 (in Chinese). 